\title{
EXPERIMENTAL STUDY OF VRATTAYATA SHAPE STEEL SILO MODELS
}

\author{
N.V. Deshpande ${ }^{1, *}$ and L.M. Gupta ${ }^{2}$ \\ ${ }^{1}$ Assistant Professor, Department of Civil Engineering, \\ K.I.T.S., Ramtek - 441106 (M.S.), INDIA \\ *(corresponding author: E-mail : deshpande narendra@yahoo.com) \\ ${ }^{2}$ Professor, Department of Applied Mechanics, VNIT, Nagpur (M.S.), INDIA \\ E-mail:lmgupta_vrce@yahoo.co.in
}

Received: 26 May 2006; Revised: 27 October 2006; Accepted: 7 November 2006

\begin{abstract}
Silos are the tall containers used to store bulk solids. The circular and rectangular shapes of silo containers are common in use. The vrattayata shape for silo containers resembles like an elongated circle. It is formed by connecting two semicircular walls of same radius with straight walls. The length of straight walls is kept as less as possible to minimize the effect of bending stresses. The behaviour of vertical walls of three such vrattayata silo models and that of one circular silo model are experimentally investigated. The volume enclosed within vertical walls of all silo models is kept unchanged to have the same capacity. The inferred static horizontal pressures from measured strains are compared with predictions by Reimbert's theory and by the method recommended in Euro Code 1 Part 4. The results obtained are discussed and conclusions are drawn.
\end{abstract}

Keywords: Silo; circular; vrattayata; reimbert's theory; stress; strain

\section{INTRODUCTION}

Many investigators all around the globe have conducted experiments to measure silo pressures and frictional wall loads to examine the validity of generally accepted design assumptions as incorporated into silo-design codes and procedures. These experiments have been carried out on circular and rectangular shapes of model silos as well as full size silos.

Lenczner [1] conducted experiments on model silo and found that the ratio of lateral pressure to vertical pressure instead of being constant as assumed in Janssen's theory, varied almost linearly with depth. Garg and Gopalkrishnan [2] in their experimentation on square silo model found that the lateral and frictional wall loads during filling and during emptying were higher than those predicted by IS4995-1968. Blight [3] found that horizontal pressures due to stored coarse material were not necessarily radially uniform as assumed in theory. Blight [3] reported about the interpretation of strain measurements on steel silos for computing inferred horizontal pressures and inferred frictional wall loads.

Reimbert's theory for silo loads is a result of mathematical interpretation of the law of hyperbolic distribution of pressures that is closely possible to the reality and includes various parameters appertaining both to the ensiled material and to the dimensional characteristics of silos. Janssen's theory accepts the hypothesis of constant value of ratio of horizontal thrust to vertical pressure in the interior of silos. Variation of this ratio is taken into account by Reimbert's Theory. 


\section{DEVELOPMENT OF CONCEPT}

\subsection{Vrattayata Shape}

The wall of circular silo is subjected to hoop tension due to lateral pressure exerted by the stored material in silo leading to the development of uniform axial tensile stresses in wall cross-section at a particular depth. The walls of square or rectangular silos are subjected to horizontal bending stresses predominantly due to lateral pressure exerted by stored material in silo at a particular depth requiring more wall thickness.

Vrattayata shape, resembling like an elongated circle, is a combination of semicircular walls and straight walls. Due to the lateral pressure exerted by stored material, semicircular walls are predominantly subjected to hoop tension and straight walls are subjected to bending moments. When the length of straight wall is reduced to a feasible level, the bending moments will also reduce.

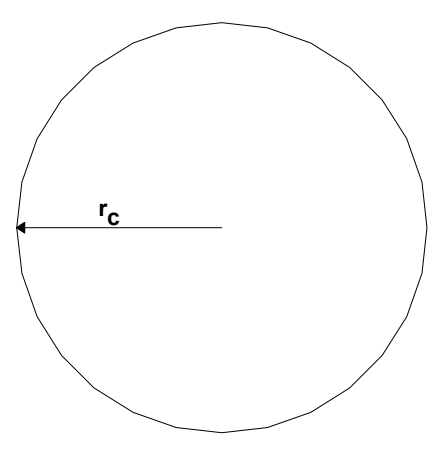

CIRCULAR

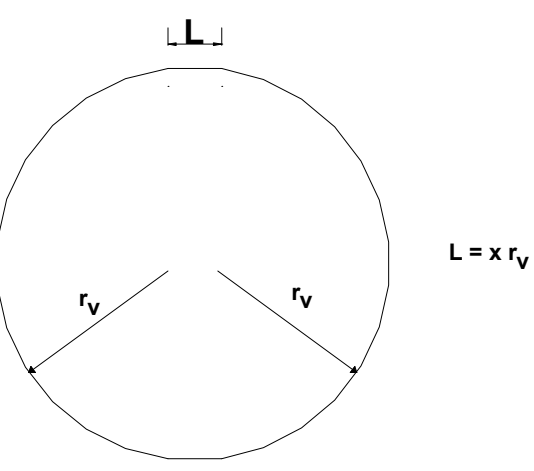

VRAYATTAYATA

Figure 1. Circular and Vrayattayata Shapes

\subsection{Geometrical Properties}

The Geometrical properties of storage container used in the silo theory are the cross-sectional area, the perimeter, the hydraulic radius, the height of wall, the volume of storage. The expressions for these properties are shown in Table 1 for circular and Vrattayata shapes.

Table 1. Expressions for Geometrical Properties of Circular and Vrattayata Shapes

\begin{tabular}{|l|l|c|c|}
\hline S. & \multicolumn{2}{|c|}{ Property } & \multicolumn{2}{|c|}{ Shapes } \\
\cline { 3 - 4 } No. & & Circular & Vrattayata \\
\hline 1 & Straight wall length (L) & - & $\mathrm{xr}_{\mathrm{v}}$ \\
\hline 2 & Cross sectional Area (A) & $\mathrm{A}_{\mathrm{c}}=\pi \mathrm{r}_{\mathrm{c}}^{2}$ & $\mathrm{~A}_{\mathrm{v}}=\mathrm{r}_{\mathrm{v}}^{2}(\pi+2 \mathrm{x})$ \\
\hline 3 & Perimeter (U) & $\mathrm{U}_{\mathrm{c}}=2 \pi \mathrm{r}_{\mathrm{c}}$ & $\mathrm{U}_{\mathrm{v}}=2 \mathrm{r}_{\mathrm{v}}(\pi+\mathrm{x})$ \\
\hline 4 & Hydraulic Radius (R) & $\mathrm{R}_{\mathrm{c}}=0.5 \mathrm{r}_{\mathrm{c}}$ & $\mathrm{R}_{\mathrm{v}}=0.5 \mathrm{r}_{\mathrm{v}} \times \frac{(\pi+2 \mathrm{x})}{(\pi+\mathrm{x})}$ \\
\hline 5 & Height of wall (H) & $\mathrm{H}_{\mathrm{c}}=\frac{\mathrm{V}}{\pi \mathrm{r}_{\mathrm{c}}^{2}}$ & $\mathrm{H}_{\mathrm{v}}=\frac{\mathrm{V}}{\mathrm{r}_{\mathrm{v}}^{2}(\pi+2 \mathrm{x})}$ \\
\hline
\end{tabular}




\section{EXPERIMENTAL INVESTIGATION}

\subsection{Models - Dimensions and Geometrical Properties}

The internal volume enclosed within vertical walls of all models is kept unchanged. The height to diameter ratio of basic circular silo model ' $\mathrm{C}$ ' is Two. The dimensions of vrattayata silo models are calculated for $\mathrm{x}=0.2$ and based upon the approaches as shown in Table 2 .

Table 2. Vrattayata Silo Models Selected for Experimental Study

\begin{tabular}{|c|c|c|c|}
\hline S1. No. & Model Referred & Approach & Property \\
\hline 1 & V12 & I & $\mathrm{U}_{\mathrm{v}}=\mathrm{U}_{\mathrm{c}}$ \\
\hline 2 & V22 & II & $\mathrm{A}_{\mathrm{v}}=\mathrm{A}_{\mathrm{c}}$ \\
\hline 3 & V32 & III & $\mathrm{R}_{\mathrm{V}}=\mathrm{R}_{\mathrm{c}}$ \\
\hline
\end{tabular}

24 Gauge B.P. sheets having average thickness of $0.6 \mathrm{~mm}$ are used in fabrication of all models. Table 3 shows dimensions of all models.

Table 3. Dimensions of Models

\begin{tabular}{|c|c|c|c|c|c|c|}
\hline S1. No. & Model & $\mathrm{r}_{\mathrm{c}}(\mathrm{mm})$ & $\mathrm{r}_{\mathrm{v}}(\mathrm{mm})$ & $\mathrm{L}(\mathrm{mm})$ & $\mathrm{H}_{\mathrm{c}}(\mathrm{mm})$ & $\mathrm{H}_{\mathrm{v}}(\mathrm{mm})$ \\
\hline 1 & $\mathrm{C}$ & 250.0 & - & - & 1000 & - \\
\hline 2 & V12 & - & 235.0 & 47.0 & - & 1004 \\
\hline 3 & V22 & - & 235.4 & 47.0 & - & 1000 \\
\hline 4 & V32 & - & 236.0 & 47.2 & - & 997 \\
\hline
\end{tabular}

\subsection{Properties}

The modulus of elasticity of wall material is found to be $1.1 \times 10^{8} \mathrm{kN} / \mathrm{m}^{2}$ while the Poisson's Ratio is 0.38 . The river bed dry sand passing through $4.75 \mathrm{~mm}$ IS sieve and retained on $1.18 \mathrm{~mm}$ IS sieve is used as stored material in all the models for the present experimental work. This sand has bulk density of $17 \mathrm{kN} / \mathrm{m}^{3}$, mean angle of internal friction as $42.72^{0}$ and mean angle of friction against wall plates as $28.28^{0}$.

\subsection{Instrumentation}

The instrumentation consists of electrical resistance strain-gauges, dummy strain gauge, digital strain meter and 20 channel box. A pair of strain-gauge consisting of one horizontal and one vertical strain-gauge is pasted in all model walls at pre-determined locations. These locations of strain-gauges measured from top are the same for all models. On vrattayata silo models, the strain-gauges are pasted on curved and straight surfaces of walls. The strain gauges used are of Type BKCT 20 with gauge length $20 \mathrm{~mm}$ and have resistance $119.2 \pm 0.2 \mathrm{ohms}$.

\subsection{Recording of Strains}

The strains in all models are recorded when the sand is fully filled in the models. Tables 4 to 7 show the strains observed on curved and straight surfaces of walls of all models. Experimental set up is shown from Figures 2 to 4. 
Table 4. Strains Observed on Curved Surface in Horizontal Direction (CX)

\begin{tabular}{|c|c|c|c|c|c|}
\hline \multirow{2}{*}{ S1. No. } & \multirow{2}{*}{$\begin{array}{l}\mathrm{y} \\
\mathrm{m}\end{array}$} & \multicolumn{4}{|c|}{ Strains (micro strains) } \\
\cline { 3 - 6 } & 0.20 & $\mathrm{C}$ & $\mathrm{V} 12$ & $\mathrm{~V} 22$ & $\mathrm{~V} 32$ \\
\hline 1 & 0.20 & 3 & 3 & 4 \\
\hline 2 & 0.35 & 8 & 5 & 6 & 6 \\
\hline 3 & 0.50 & 10 & 6 & 8 & 8 \\
\hline 4 & 0.65 & 11 & 8 & 9 & 9 \\
\hline 5 & 0.80 & 8 & 7 & 7 & 8 \\
\hline
\end{tabular}

Table 5. Strains Observed on Curved Surface in Vertical Direction (CY)

\begin{tabular}{|c|c|c|c|c|c|}
\hline \multirow{2}{*}{ S1. No. } & \multirow{2}{*}{$\begin{array}{c}\mathrm{Y} \\
(\mathrm{m})\end{array}$} & \multicolumn{4}{|c|}{ Strains (micro strains) } \\
\hline & & $\mathrm{C}$ & V12 & V22 & V32 \\
\hline 1 & 0.20 & 1 & 1 & 1 & 1 \\
\hline 2 & 0.35 & 2 & 1 & 2 & 2 \\
\hline 3 & 0.50 & 0 & 2 & 3 & 2 \\
\hline 4 & 0.65 & 3 & 3 & 4 & 3 \\
\hline 5 & 0.80 & 4 & 5 & 4 & 4 \\
\hline
\end{tabular}

Table 6. Strains Observed on Straight Surface in Horizontal Direction (SX)

\begin{tabular}{|c|c|c|c|c|}
\hline \multirow{2}{*}{ S1. No. } & \multirow{2}{*}{$\begin{array}{c}\text { Y } \\
(\mathrm{m})\end{array}$} & \multicolumn{3}{|c|}{ Strains (micro strains) } \\
\cline { 3 - 5 } & & $\mathrm{V} 12$ & $\mathrm{~V} 22$ & $\mathrm{~V} 32$ \\
\hline 1 & 0.20 & 0 & 2 & 4 \\
\hline 2 & 0.35 & $*$ & $*$ & 7 \\
\hline 3 & 0.50 & 4 & 7 & 8 \\
\hline 4 & 0.65 & 7 & 9 & $*$ \\
\hline 5 & 0.80 & 8 & 8 & 8 \\
\hline
\end{tabular}

Table 7. Strains Observed on Straight Surface in Vertical Direction (SY)

\begin{tabular}{|c|c|c|c|c|}
\hline \multirow{2}{*}{ S1. No. } & \multirow{2}{*}{$\begin{array}{c}\mathrm{Y} \\
(\mathrm{m})\end{array}$} & \multicolumn{3}{|c|}{ Strains (micro strains) } \\
\cline { 3 - 5 } & & $\mathrm{V} 12$ & $\mathrm{~V} 22$ & $\mathrm{~V} 32$ \\
\hline 1 & 0.20 & 0 & 2 & 3 \\
\hline 2 & 0.35 & 1 & 2 & 2 \\
\hline 3 & 0.50 & 6 & 2 & $*$ \\
\hline 4 & 0.65 & 3 & 4 & 4 \\
\hline 5 & 0.80 & 4 & 5 & 4 \\
\hline
\end{tabular}

* indicates failure of strain gauges 


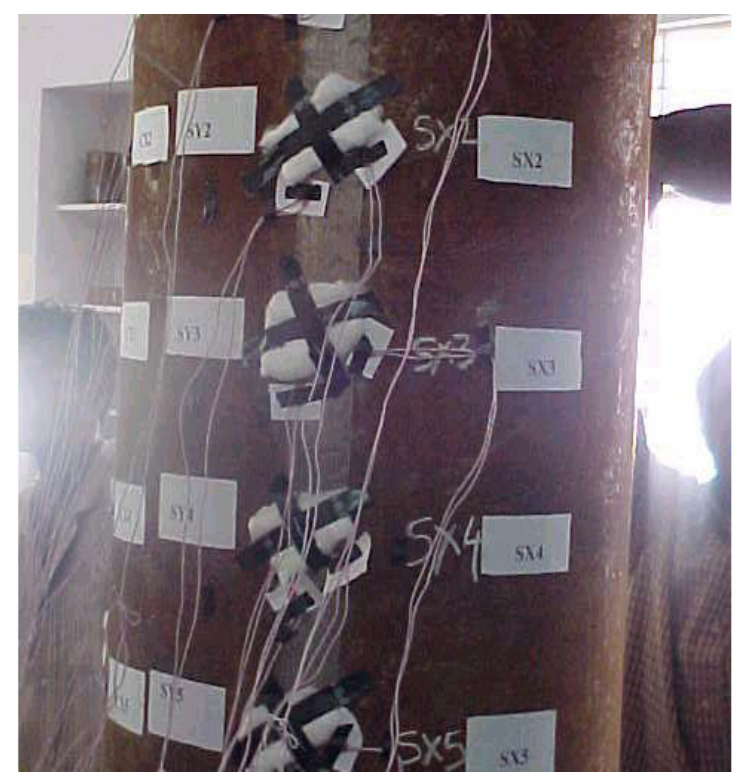

Figure 2. Marking of Strain-gauges

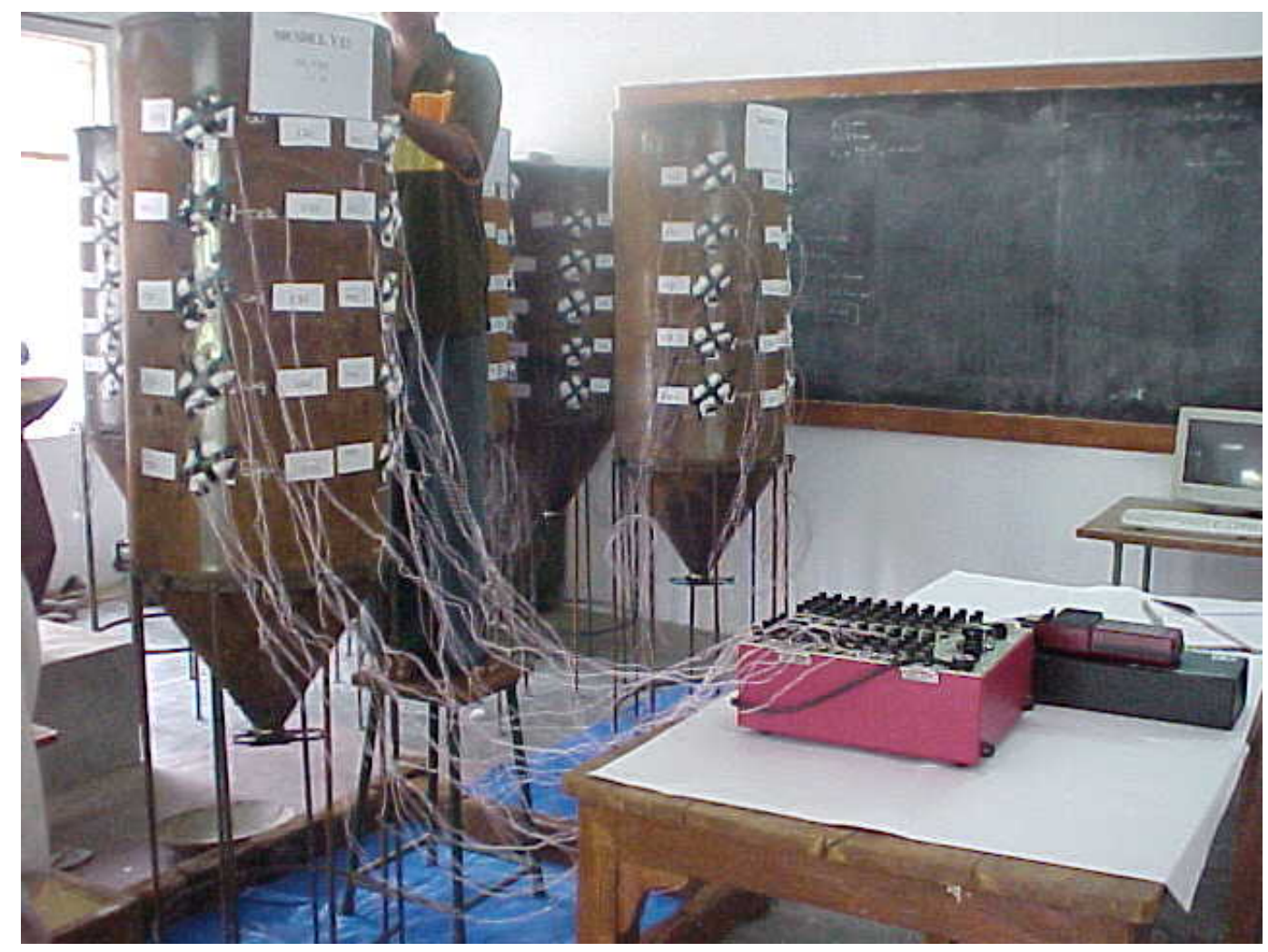

Figure 3. Silo Model Filled with Sand 


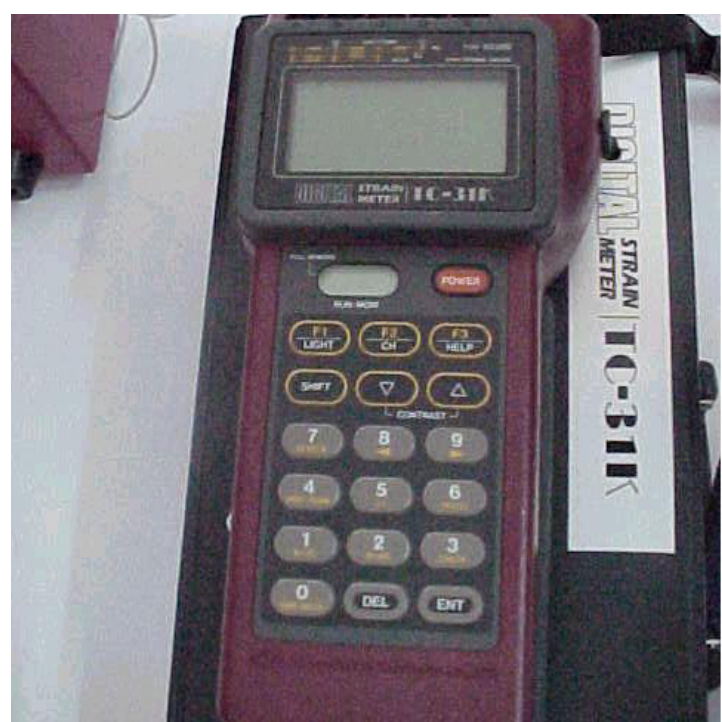

Figure 4. Digital Strain Indicator

\subsection{Inferred Pressures}

The static horizontal pressures developed in the walls of silo models as computed from observed strains are termed as inferred pressures. They are computed using following relationships.

$$
\begin{aligned}
& \mathrm{S}_{\mathrm{x}}=\frac{\mathrm{E}}{\left(1-v^{2}\right)}\left(\varepsilon_{\mathrm{x}}+v \varepsilon_{\mathrm{y}}\right) \\
& \mathrm{p}=\frac{2 \mathrm{~S}_{\mathrm{x}} \mathrm{t}}{\mathrm{D}}
\end{aligned}
$$

Where $\mathrm{D}=$ Mean diameter of circular model silo and $\mathrm{D}=$ Mean diameter of inscribed circle in cross-section of Vrattayata model silos.

\subsection{Pressures by Reimbert's Theory}

The following equations according to Reimbert's theory are used to compute the static horizontal pressures developed on walls of all silo models.

For circular model

$\mathrm{p}=\frac{\mathrm{WR}_{\mathrm{c}}}{\mu}\left[1-\left(\frac{Y}{\mathrm{C}_{\mathrm{c}}}+1\right)^{-2}\right]$

Where $\mathrm{C}_{\mathrm{c}}=\frac{\mathrm{R}_{\mathrm{c}}}{\mu \mathrm{K}}$

For Vrattayata Models

$\mathrm{p}=\frac{\mathrm{WR}_{\mathrm{v}}}{\mu}\left[1-\left(\frac{Y}{\mathrm{C}_{v}}+1\right)^{-2}\right]$

Where $\mathrm{C}_{\mathrm{v}}=\frac{(\pi+\mathrm{x}) \mathrm{r}_{\mathrm{v}}}{2 \pi \mu \mathrm{K}}$ 


\subsection{Euro Code}

The expressions for computing the horizontal pressure exerted on vertical walls of silo under fully filled condition as per Euro Code 1 part 4 are as follows :

$\mathrm{p}=\frac{\mathrm{WR}}{\mu}\left[1-\mathrm{e}^{\frac{-k \mu Y}{R}}\right]$

The code also suggests that for computing $\mathrm{p}, \quad \mu=0.9 \mu_{\mathrm{m}}$ and $\mathrm{k}=1.15 \mathrm{~K}_{\mathrm{m}}$. The value of $\mathrm{K}_{\mathrm{m}}$ is considered as $1.1(1-\sin \phi)$.

\section{RESULTS}

The strains recorded during conduction of experiments on all Silo models are used to determine inferred horizontal pressures on walls at predetermined positions of strain-gauges.

The horizontal pressures at strain-gauge positions are computed using Reimbert's theory and by applying Euro code method.

The comparison is shown in Table 8 and 9 for models C, V12, V22, V32.

Table 8. Comparison of $\mathrm{p}$ for Model ' $\mathrm{C}$ ' \& ' $\mathrm{V} 12$ '

\begin{tabular}{|c|c|c|c|c|c|c|c|c|}
\hline & \multirow{2}{*}{\multicolumn{3}{|c|}{$\begin{array}{l}\text { FOR C } \\
\mathrm{p}\left(\mathrm{kN} / \mathrm{m}^{2}\right)\end{array}$}} & \multirow{2}{*}{\multicolumn{4}{|c|}{$\frac{\text { FOR V12 }}{\mathrm{p}\left(\mathrm{kN} / \mathrm{m}^{2}\right)}$}} \\
\hline \multirow{2}{*}{$\begin{array}{l}\text { Sl. } \\
\text { No. }\end{array}$} & \multirow{2}{*}{$\begin{array}{c}\mathrm{Y} \\
(\mathrm{m})\end{array}$} & & & & & & & \\
\hline & & EURO & Reim & $\mathrm{MC}$ & EURO & Reim & $\mathrm{MC}$ & $\mathrm{MS}$ \\
\hline 1 & 0.20 & 1.305 & 1.071 & 1.35 & 1.304 & 1.066 & 1.1 & 0 \\
\hline 2 & 0.35 & 2.047 & 1.615 & 2.7 & 2.044 & 1.608 & 1.76 & $*$ \\
\hline 3 & 0.50 & 2.632 & 2.02 & 3.08 & 2.682 & 2.011 & 2.21 & 2.06 \\
\hline 4 & 0.65 & 3.094 & 2.33 & 3.74 & 3.089 & 2.32 & 2.99 & 2.67 \\
\hline 5 & 0.80 & 3.459 & 2.57 & 2.93 & 3.45 & 2.562 & 2.92 & 3.12 \\
\hline
\end{tabular}

MC indicates inferred pressures on curved wall and MS indicates inferred pressures on straight wall.

Table 9. Comparison of $\mathrm{p}$ for Model 'V22' \& 'V32'

\begin{tabular}{|c|c|c|c|c|c|c|c|c|c|}
\cline { 3 - 10 } \multicolumn{2}{c|}{} & \multicolumn{4}{c|}{ FOR V22 } & \multicolumn{5}{c|}{ FOR V32 } \\
\hline Sl. & \multirow{2}{*}{ Y $(\mathrm{kN})$} & \multicolumn{3}{|c|}{$\left.\mathrm{m}^{2}\right)$} & \multicolumn{4}{c|}{$\left.\mathrm{m}^{2}\right)$} \\
\cline { 3 - 11 } & & EURO & Reim & MC & MS & EURO & Reim & MC & MS \\
\hline 1 & 0.20 & 1.304 & 1.066 & 1.107 & 0.9 & 1.305 & 1.066 & 1.43 & 1.68 \\
\hline 2 & 0.35 & 2.045 & 1.608 & 2.214 & $*$ & 2.047 & 1.609 & 2.206 & 2.53 \\
\hline 3 & 0.50 & 2.683 & 2.013 & 2.995 & 2.54 & 2.632 & 2.014 & 2.86 & $*$ \\
\hline 4 & 0.65 & 3.091 & 2.322 & 3.44 & 3.44 & 3.094 & 2.324 & 3.31 & $*$ \\
\hline 5 & 0.80 & 3.455 & 2.564 & 2.79 & 3.24 & 3.459 & 2.566 & 3.1 & 3.1 \\
\hline
\end{tabular}

Figures 5 to 8 show variation of static horizontal pressures along depth of vertical wall of model C, V12, V22, V32 respectively. 


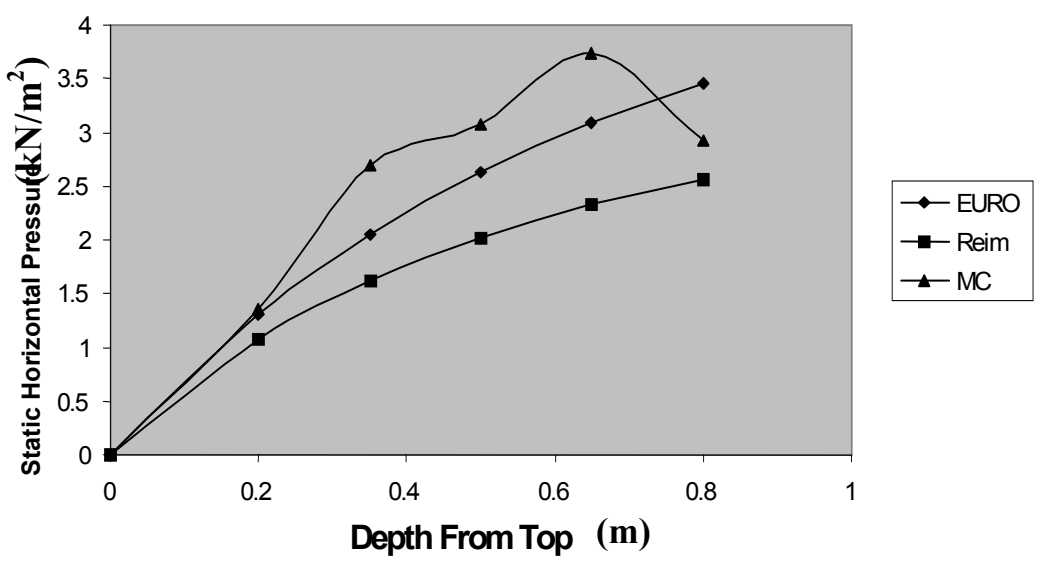

Figure 5. Variation of Horizontal Pressure Model - C

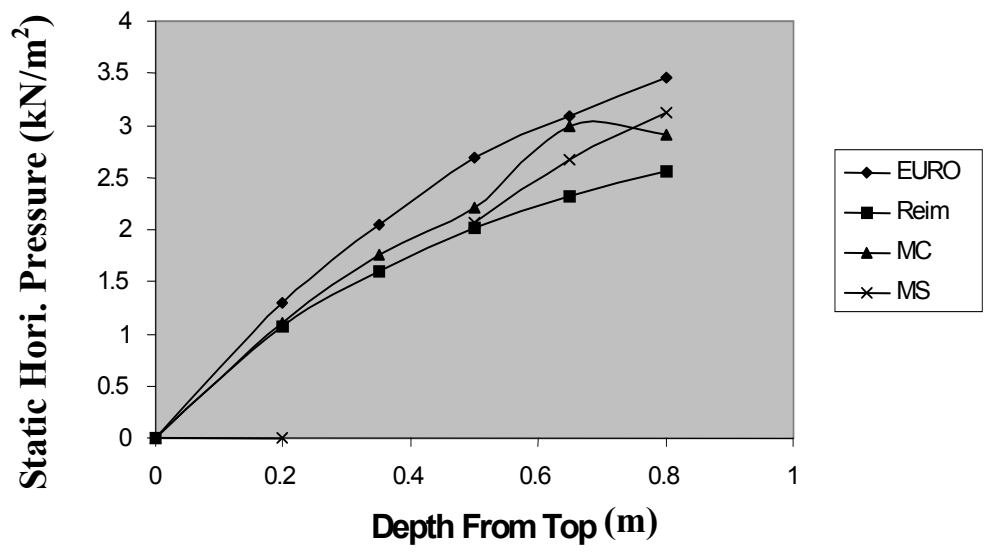

Figure 6. Variation of Horizontal Pressure Model - V12

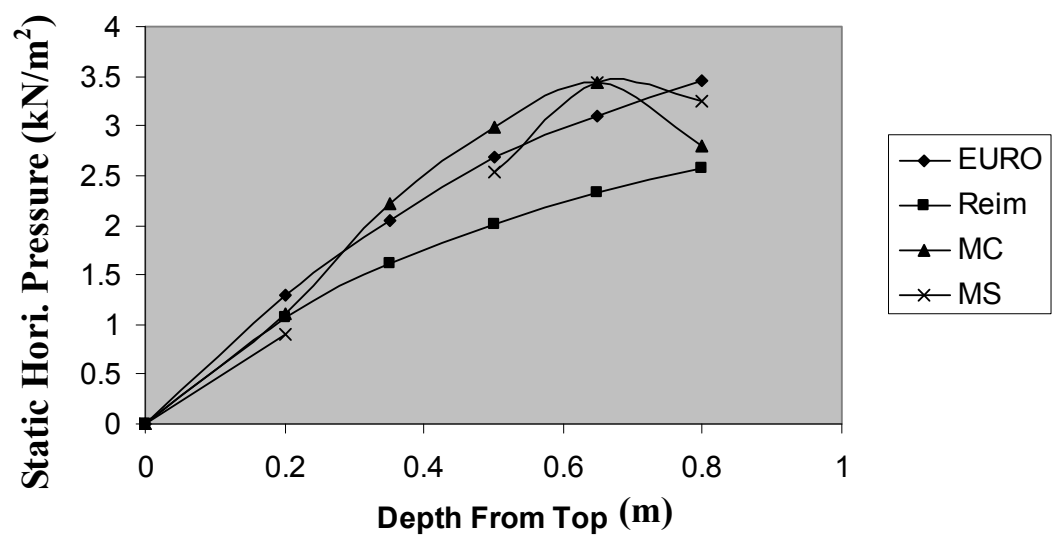

Figure 7. Variation of Static Horizontal Pressure Model - V22

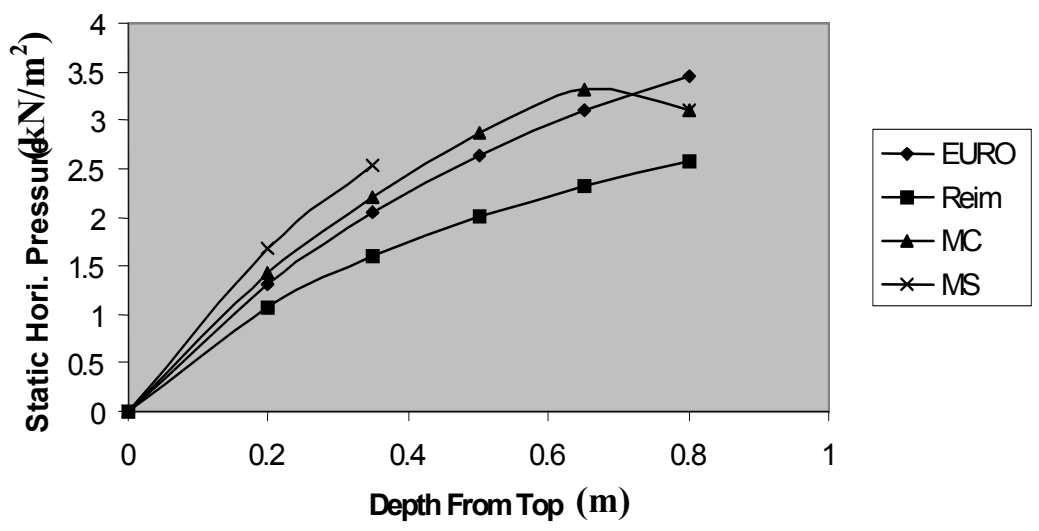

Figure 8. Variation of Static Horizontal Pressure Model - V32 


\section{DISCUSSION}

- The ratio of length of straight portion to radius of semicircular portion in Vrattayata shape models is selected as 0.2 so that some feasible dimension from fabrication point of view is possible.

- The internal volume enclosed within vertical walls of all silo models is kept unchanged so that the same quantity of material in all models can be filled.

- Moisture free dry sand is used as stored material as dampness in sand affects its characteristics.

- $\quad$ The thickness of sheet used in model silos being very small, it is susceptible for melting in arc welding. Hence, spot welding is used with specific current rating.

- The principal characteristics $(\mathrm{W}, \phi, \delta)$ of stored material are determined in the laboratory to have their appropriate values rather than selecting them from standard books or codes.

- The static horizontal pressures on walls of model silos are computed using two dimensional stress-strain relationship in which measured horizontal and vertical strains are assumed to be principal strains.

- $\quad$ The static horizontal pressures computed from measured strains on wall of Model $\mathrm{C}$ and curved walls of Model V12, V22, V32 show similar trend as obtained by Euro Code Method and Reimbert's theory. But the curve is closer to curve as obtained by Euro Code Method than Reimbert's theory. Generally, these pressures on curved surfaces are more than those predicted by Reimbert's theory predictions at corresponding depths.

- The assumption that the inferred pressures at a particular depth would be the same at curved wall and at straight wall of Vrattayata models does not appear to be correct as differences are seen between the inferred pressures at a particular depth on curved wall and on straight wall. In the models V22, V32, the trend observed for inferred pressures on straight wall is the same as that for curved wall. But in the Model V12, such trend is seen only in lower half of the wall. This may be due to disturbances in stresses caused at the joints between the straight wall and curved wall and the development of small magnitude bending stresses. The trend of increase in inferred pressures along the depth of straight wall is seen generally in most of the models. These curves are closer to curves predicted by Euro Code Method than by Reimbert's theory.

- $\quad$ The main reasons for observed differences at many points are as follows.

o Material used for wall does not possess the same properties everywhere.

o Creation of imperfections in model walls during process of fabrication.

o The stiffener plates provided at top and bottom of model walls affect the strains. Such plates are not envisaged from the predictions by Euro Code Method and Reimbert's theory.

o The bulk density of sand, which is used as stored material, varies along the depth.

- The ratio of lateral pressure to vertical pressure actually varies along the depth of silo wall. This variation of pressure ratio is appropriately considered in Reimbert's theory by considering suitably the characteristic abscissa in its formulation.

- When static horizontal pressures are calculated following guidelines of Euro code 1 part 4 (1996) for all four models at $0.5 \mathrm{~m}$ depth, it is observed that the variation between these pressures and corresponding inferred pressures is not more than $27 \%$. 


\section{CONCLUSIONS}

1. For Vrattayata shape, three dimensions, its radius of semi-circular portion, its length of straight portion and its height can decide its volume content, but in circular shape only two dimensions, its radius and height can decide its volume content.

2. Reimbert's theory for silo takes into account the effect of shape by considering the characteristic abscissa in predicting the wall pressures.

3. Slight imperfection in silo geometry causes increase in pressure.

4. The measured strains in a particular vrattayata silo model at the same depth are not the same on curved walls and straight walls.

\section{REFERENCES}

[1] Lenczner, D., "An Investigation into the Behavior of Sand in a Model Silo”, The Structural Engineer, December 1963, Vol. 41, pp. $389-398$.

[2] Garg, R.M. and Gopalkrishnan, S., "An Experimental Investigation of Wall Loads in Wheat Silos", Indian Concrete Journal, October 1974, pp. 308-313.

[3] Blight, G.E., "Pressures Exerted by Materials Stored in Silos : Part I, Coarse Materials", Journal of Geotechnique, Vol. 36, No. 1, 1986, pp. 33-46.

[4] Blight, G.E., "Pressures Exerted by Materials Stored in Silos : Part II, Fine Powders", Journal of Geotechnique, Vol. 36, No. 1, 1986, pp. $47-56$.

[5] Eurocode 1 : DD ENV 1991 - 4 : 1996, "Basis of Design and Actions on Structures", Part 4. Actions in Silos and Tanks, British Standards Institutions.

[6] Reimbert, M.L. and Reimbert, A.M., "Silos Theory and Practice", Trans Tech Publications, 1976, Vol. 1, No. 3.

[7] Safarian, S.S., Harris, E.C., "Design and Construction of Silos and Bunkers", Publishers Van Nostrand Reinhold Company, New York, U.S.A., 1985. 


\section{NOTATIONS}

A Area of horizontal cross-section through silo $\left(\mathrm{m}^{2}\right)$

$A_{c}, A_{v}$ Area of horizontal cross - section through circular and Vrattayata silos respectively. $\left(\mathrm{m}^{2}\right)$

$\mathrm{C}_{\mathrm{c}}, \mathrm{C}_{\mathrm{v}}$ Reimbert's characteristic abscissa for circular and Vrattayata silos respectively

E Modulus of Elasticity $\left(\mathrm{kN} / \mathrm{m}^{2}\right)$

$\mathrm{H} \quad$ Height of vertical wall of silo (m)

$\mathrm{H}_{\mathrm{c}}, \mathrm{H}_{\mathrm{v}}$ Height of vertical wall for circular and Vrattayata silos respectively (m)

$\mathrm{L} \quad$ Length of Straight portion of the wall of Vrattayata silo (m)

$\mathrm{R} \quad$ Hydraulic Radius ( A / U ) (m)

$\mathrm{R}_{\mathrm{c}}, \mathrm{R}_{\mathrm{v}}$ The hydraulic radius for circular and Vrattayata shape silos respectively (m)

$\mathrm{S}_{\mathrm{x}} \quad$ Stress in $\mathrm{X}$ direction $\left(\mathrm{kN} / \mathrm{m}^{2}\right)$

$\mathrm{U} \quad$ Perimeter of horizontal cross - section $(\mathrm{m})$

$U_{c}, U_{v}$ Perimeter of horizontal cross - section of circular and Vrattayata silos respectively (m)

$\mathrm{V} \quad$ Internal volume of container enclosed by vertical wall of silo $\left(\mathrm{m}^{3}\right)$

W Bulk Density of stored material $\left(\mathrm{kN} / \mathrm{m}^{3}\right)$

$\mathrm{Y} \quad$ Depth of stored material above the point in question (m)

$\mathrm{k} \quad$ Ratio of horizontal to vertical pressure by stored material

$\mathrm{K}_{\mathrm{m}} \quad$ Mean value of ratio of horizontal to vertical pressure by stored material

$\mathrm{p} \quad$ Static horizontal pressure on silo walls due to stored material $\left(\mathrm{kN} / \mathrm{m}^{2}\right)$

$r_{c} \quad$ Internal radius of circular silo $(\mathrm{m})$

$r_{v} \quad$ Internal radius of semi - circular portion of Vrattayata silo (m)

$\mathrm{t} \quad$ Thickness of wall (mm)

$\mathrm{x}$ The ratio of length of straight portion to radius of semi - circular portion of Vrattayata silo $\left(\mathrm{L} / \mathrm{r}_{\mathrm{v}}\right)$

$\mu \quad$ The coefficient of wall friction $(\tan \delta)$

$\mu_{\mathrm{m}} \quad$ Mean coefficient of wall friction

$\phi \quad$ The angle of internal friction of stored material

$\delta \quad$ The angle of wall friction

$v \quad$ Poisson's ratio for wall material

$\varepsilon_{\mathrm{x}}, \varepsilon_{\mathrm{y}} \quad$ Measured strains in $\mathrm{X}$ and $\mathrm{Y}$ directions respectively 